Методы спектроскопии

\title{
ИСПОЛЬЗОВАНИЕ ИНФРАКРАСНОЙ СПЕКТРОСКОПИИ И СПЕКТРОСКОПИИ КОМБИНАЦИОННОГО РАССЕЯНИЯ ДЛЯ АНАЛИЗА СОСТОЯНИЯ БИОМОЛЕКУЛ У ЛИНИЙ КУКУРУЗЫ Zea mays L.*
}

\author{
C.N. RADENOVICH ${ }^{1,5}{ }^{\bowtie}$, Г.B. MAKCИMOB ${ }^{2}{ }^{凶}$, B.B. ШУTOBA ${ }^{3}$, J. HAO $^{4}$, \\ N.S. DELICH ${ }^{1}$, M.D. SECHANSKY ${ }^{1}$, A.S. POPOVICH ${ }^{1}$
}

В настоящее время мало неинвазивных методов, которые позволяют контролировать содержание и конформацию молекул биоактивных органических соединений в клетках и тканях растений не только в лабораторных, но и в полевых условиях. Инфракрасная спектроскопия и спектроскопия комбинационного рассеяния (ИК- и КР-спектроскопия) активно используется для анализа роли молекул некоторых веществ в селекции сельскохозяйственных культур. С помощью методов вибронной спектроскопии мы исследовали изменения содержания и конформации молекул хлоропластов у различных линий кукурузы. Методом ИК-спектроскопии (область 3500-3000 $\mathrm{cm}^{-1}$ ) установлено, что в воде, углеводах и белках хлоропластов доля колебаний ОН-групп и внутри- и межмолекулярных Н-связей максимальна у линии кукурузы ZPPL 186, а колебаний NH-групI амидов (белки) минимальна у линии ZPPL 225. Доказано, что для линии ZPPL 186 характерна максимальная доля колебаний от молекул алканов, карбоновых кислот (область 2920-2860 см-1) и деформационных колебаний ароматических структур (полоса $1000 \mathrm{~cm}^{-1}$ ), находящихся в хлоропластах, тогда как для линии M1-3-3-sdms - доля валентных колебания $O=C=O$ связей (полоса $\left.2300 \mathrm{~cm}^{-1}\right)$. С использованием КР-спектроскопии (области 1250-500 см-1 и 1535-1400 см-1) обнаружено, что различия в спектрах между линиями кукурузы связаны с выявленными изменениями конформации молекул каротиноидов в хлоропластах, но не молекул целлюлозы. Установлено, что у всех образцов (кроме ZPPL 225) молекулы каротиноидов находятся в 15-trans форме с различной конформацией полиеновой цепи. Отметим, что у линии ZPPL 186 конформация каротиноидов, находящихся в хлоропластах, характеризуется минимальной величиной поворота вне плоскости полиеновой цепи и более выраженными колебаниями боковой СН3-группы. Высказывает предположение, что у изученных линий кукурузы каротиноиды хлоропластов листа не взаимодействуют с ароматическими аминокислотами белков. По мнению авторов, сочетание методов ИК- и КРспектроскопии хлоропластов листа можно рекомендовать для контроля за содержанием и конформациоными изменениями биомолекул при селекции кукурузы.

Ключевые слова: Zea mays L., инбредная линия, лист, хлоропласты, спектры комбинационного рассеяния, инфракрасные спектры, конформационные изменения, углеводы, каротиноиды, белки, селекционное тестирование.

Рост населения на планете повышает требования к урожайности и рентабельности производства продуктов сельского хозяйства, что может быть достигнуто благодаря фундаментальным исследованиям, позволяющим разработать эффективные аналитические методы для применения в селекции растений (1-3). В настоящее время мало неинвазивных методов, которые позволяют контролировать содержание и изменение конформации молекул биоактивных органических соединений в клетках и тканях растений не только в лабораторных, но и в полевых условиях. ИК- и КР-спектроскопия активно используется для изучения роли молекул некоторых веществ в селекции сельскохозяйственных культур (3-6). В большинстве случаев измерения с помощью указанных методов можно проводить в полевых условиях непосредственно на тканях растений, а также на фракциях, выделенных из растительного материала. Оба метода вибронной спектроскопии позволяют не только регистрировать спектры, полосы которых характеризуют содержание и конформационные изменения определенных молекул (7-9), но и на основании этих данных различать генотипы растений $(1,2)$. Возможность

\footnotetext{
* Исследования проводятся в Сербии и в Российской Федерации под руководством профессора C.N. Radenovich (г. Белград, Сербия) и профессора Г.В. Максимова (г. Москва, Россия) и финансируются национальными министерствами и ведомствами (РНФ для ГВМ № 19-79- 30062). 
быстрого мониторинга количества и физико-химического состояния биоактивных органических соединений и клеточных компартментов (например, каротиноидов и хлоропластов) в гомогенатах листьев растений и выявление корреляции этих показателей с хозяйственно значимыми признаками позволило бы использовать регистрируемые при спектроскопии параметры как маркеры для оценки агрономической эффективности исследуемых форм при селекции растений. Кроме того, эти методы могут применяться в обрабатывающей промышленности для быстрой проверки качества поступающего сырья, а также для контроля на непрерывных производствах (10-12). На основе анализа ИК-спектров у растений были получены дополнительные характеристики не только структуры различных молекул, но и модификации их конформации (по изменению доли характерных колебаний химических связей в молекулах) (13-15).

В отличие от ИК-спектроскопии, КР-спектроскопия позволяет контролировать изменения структуры молекул в клетках и тканях без высушивания препаратов $(3,12,16-18)$. С помощью этого метода описаны особенности и различия в распределении молекул белков и пигментов в клетках растений у разных гибридов и линий кукурузы. Важно, что такой подход позволяет выявить наличие положительной корреляции между изменением флуоресценции хлорофилла в хлоропластах и содержанием и структурой молекул каротиноидов в целых листьях у линий и гибридов кукурузы $(3,18)$.

Очевидно, что формирование методологии исследования функционального состояния растения с помощью спектральных методов позволит выявить новые молекулярные механизмы, которые могут быть использованы в селекции кукурузы.

В настоящей работе доказано, что совместное использование ИК- и КР-спектроскопии листа растения можно рекомендовать в качестве малоинвазивного метода контроля за содержанием и возможными различиями в конформации биологических молекул при тестировании линий и гибридов кукурузы.

Цель работы заключалась в комплексном анализе изменений содержания и конформации молекул белков, углеводов и пигментов в хлоропластах листа у инбредных линий кукурузы методами ИК- и КР-спектроскопии.

Mетодика. Эксперименты выполняли на линиях кукурузы (Zea mays L.) ZPPL 186, ZPPL 225, M1-3-3-sdms, оригинатор - Maize Research Institute, Zemun Polje, г. Белград, Сербия), которые характеризуются высокими показателями качества, урожайности и адаптированы к технологиям возделывания $(1,3,12)$. По 30 семян каждой линии (масса соответственно от $313 \pm 9$, $382 \pm 17$ и $196 \pm 5$ мг) обрабатывали в течение 30 мин перекисью водорода, промывали водой и оставляли в чашке Петри $\left(22{ }^{\circ} \mathrm{C}\right.$, постоянное бесконтактное смачивание водой) до появления корешков длиной не менее 5 мм, после чего проросшие семена помещали в грунт и выращивали до фазы 3-го листа (16-часовой световой день; лабораторный опыт). Качество используемых семян оценивали по всхожести (способность семян прорастать и давать нормально развитые проростки при определенных условиях за принятые сроки; ГОСТ 13056.6-75) и энергии прорастания (способность семян прорастать за более короткий срок - от 1 до 15 сут; ГОСТ 13056.6-75).

Для получения хлоропластов охлажденную $\left(0-4{ }^{\circ} \mathrm{C}\right)$ навеску листьев (5 г, образцы находились в полиэтиленовом пакете или во влажной фильтровальной бумаге), отделяли от жилок, измельчали ножницами и гомогенизировали при $0-4{ }^{\circ} \mathrm{C}$ трижды (по 10 с) в охлажденном буфере $\left(4{ }^{\circ} \mathrm{C}\right)(0,04 \mathrm{M}$ 
сахароза, 20 мM Tris- $\mathrm{HCl}, \mathrm{pH}$ 7,8, $35 \mathrm{mM} \mathrm{NaCl,} 1$ мM EDTA). Гомогенат фильтровали через четыре слоя капрона и центрифугировали (1500 об/мин, 5 мин, 0-4 $\left.{ }^{\circ} \mathrm{C}\right)$. Супернатант переливали в предварительно охлажденные пробирки и снова центрифугировали (5000 об/мин, $44{ }^{\circ} \mathrm{C}, 10$ мин). Супернатант сливали, полученный осадок ресуспендировали в 5 мл среды выделения. Добавляли глицерин (30\% от полученного объема) и замораживали при $-73{ }^{\circ} \mathrm{C}$. Перед регистрацией КР- и ИК-спектров суспензию размораживали и разводили буфером (15 мМ NaCl, 400 мМ сахароза, 50 мM Mes- $\mathrm{NaOH}, \mathrm{pH}$ $6,5)$ в соотношении 10 мкл суспензии на 5 мл буфера $(19,20)$.

Целлюлозу выделяли из листьев кукурузы согласно описанию (21) с использованием $3 \%$ раствора гипохлорита натрия, $5 \%$ раствора пероксида водорода и смеси $3 \%$ раствора гипохлорита натрия и метанола.

Комбинационное рассеяние каротиноидов в хлоропластах листа регистрировали с помощью КР-спектрометра ДФС 24 (АО «ЛОМО», Россия) с лазером (Ciel, «Eurolaser $\mathrm{GmbH»,} \mathrm{Германия)} \mathrm{(длина} \mathrm{волны} 473$ нм), системой регистрации МОРС 1/3648 (ООО «МОРС», г. Троицк, Россия) на базе линейной ПЗС-матрицы TCD1304DG («Toshiba», Япония) с фильтром LPO2-473RS-50 («Semrock», США). Мощность лазера на образце составляла 3 мВт, время регистрации сигнала - 10 с (23).

Регистрацию ИК-спектров в диапазоне 400-4000 см-1 с преобразованием Фурье (ИК-Фурье спектрометрия) проводили с помощью ИК-спектрометра IR-Prestig 21 («Shimadzu Corp.», Япония) с шагом измерения $4 \mathrm{~cm}^{-1}$. Перед экспериментом суспензию гомогената листа (см. выше) размораживали и разводили буфером (15 мM NaCl, 400 мМ сахароза и 50 мM Mes$\mathrm{NaOH}, \mathrm{pH} 6,5 ; 10$ мкл суспензии на 5 мл буфера), высушивали и закатывали в таблетку с бромидом калия (KBr) (соотношение компонентов 1:50) $(12,23)$.

Статистическую обработку результатов проводили с помощью программы Microsoft Excel 2013 («Microsoft Corp.», США) и пакета Statistica v.10 («StatSoft, Inc.», США). Первичнаую обработку КР- и ИК-спектров проводили с помощью пакета Origin Pro 2017 («OriginLab Corp.», США). Проверка статистических гипотез осуществлялась непараметрическим Н-критерием для множества независимых переменных Краскела-Уоллиса (Kruskal-Wallis test) (уровень значимости $\mathrm{p}=0,05 ; n=10$ ).

Результаты. Задачи нашего исследования включали регистрацию ИК-спектров хлоропластов у трех линий кукурузы и анализ различий между ними для молекул белков и углеводов, а также проведение дополнительно КР-спектроскопии для выявления изменений каротиноидов, содержащихся в хлоропластах. В ИК-спектрах хлоропластов в диапазоне 4000-400 см-1 были обнаружены полосы, обусловленные колебаниями связей в молекулах ряда органических соединений, включая целлюлозу, белки, углеводы, эфиры, фенолы (рис. 1).

Было установлено, что в ИК-спектре хлоропластов в области 3700$3100 \mathrm{~cm}^{-1}$ присутствовали полосы, соответствующие колебаниям гидроксильных групп, а в области 1500-900 $\mathrm{cm}^{-1}-$ колебаниям $\mathrm{C}-\mathrm{H}, \mathrm{C}-\mathrm{O}$ и O-H групп гликозидной связи и глюкопиранозного кольца молекул целлюлозы (13-15). Так, полоса $3340 \mathrm{~cm}^{-1}$ ИК-спектра характеризует колебания О-Н и СН2-ОН связей целлюлозы, полосы 2900 и 1374 см$^{-1}$ - деформационные колебания С-Н групп, а полосы 1170 и $1059 \mathrm{~cm}^{-1}-$ колебания соответственно связей $\mathrm{C}-\mathrm{O}-\mathrm{C}$ и С-OН. В ИК-спектре хлоропластов листа присутствовала полоса 3414 см$^{-1}$, обусловленная валентными колебаниями гидроксильных групп, и полоса при $2904 \mathrm{~cm}^{-1}$, характеризующая колебания $\mathrm{C}-\mathrm{H}$ метиленовых и метиновых групп молекул. Также в ИК-спектре выявили полосу $1654 \mathrm{~cm}^{-1}$, обусловленную $\mathrm{H}-\mathrm{O}-\mathrm{H}$ колебаниям в кристал- 
лизованной воде, полосу $1375 \mathrm{~cm}^{-1}$, вызванную деформационными колебаниями С-Н связи, и полосу $1317 \mathrm{~cm}^{-1}$, которая характеризует деформационные колебания $\mathrm{CH}_{2}$-групп молекул. Полоса $1165 \mathrm{~cm}^{-1}$ в ИК-спектре соответствует валентным колебаниям С-O-C связи, однако ее также относят к деформационным колебаниям $\mathrm{C}-\mathrm{O}$ или $\mathrm{O}-\mathrm{H}$ в $\mathrm{C}-\mathrm{OH}$ группах молекул. Полоса ИК-спектра при $1085 \mathrm{~cm}^{-1}$ соответствует колебаниям связи С-O-C в глюкопиранозном кольце, полоса $1058 \mathrm{~cm}^{-1}$ характеризует валентное колебание $\mathrm{C}-\mathrm{O}$ связи в $\mathrm{C}_{3} \mathrm{H}-\mathrm{OH}$ группе, а полосы 796 и 777 см$^{-1}$ отражают колебания глюкопиранозного кольца, связанные с колебаниями СН- и СН2-групп. Полосы, выявленные в ИК-спектрах в области 1500-1650 см-1, соответствуют белкам.

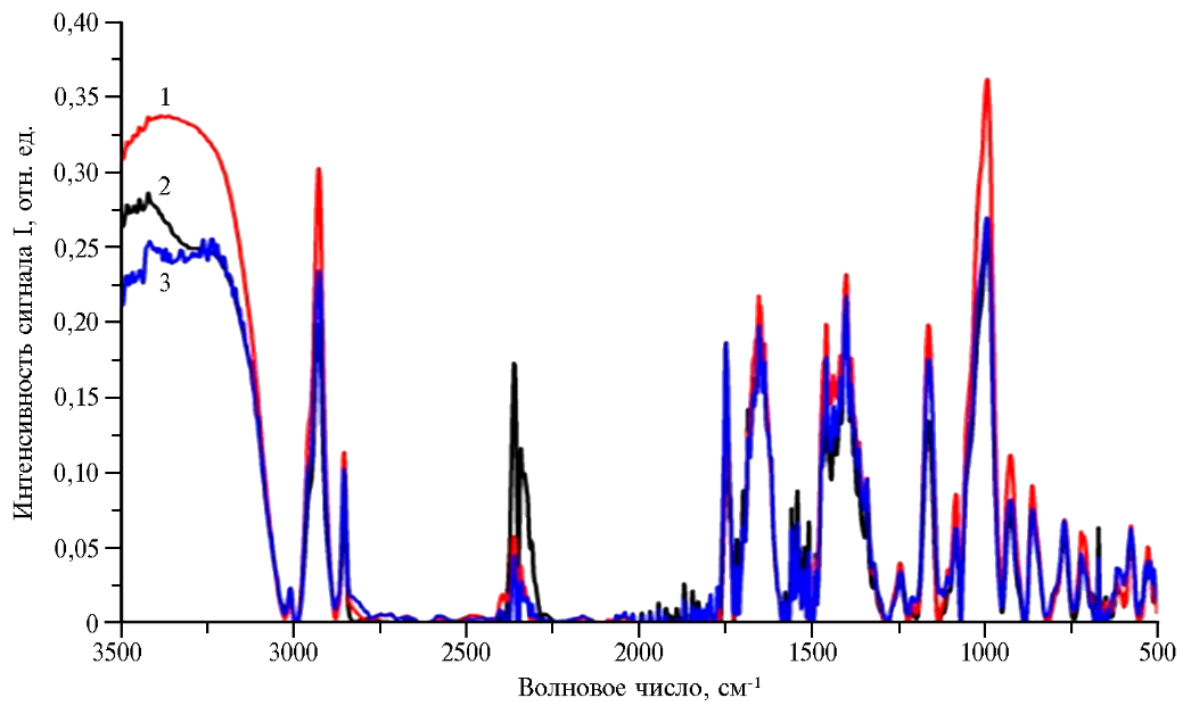

Рис. 1. ИК-спектры (инфракрасная спектроскопия с преобразованием Фурье) хлоропластов листа кукурузы (Zea mays L.) линий ZPPL 186 (1), M1-3-3-sdms (2) и ZPPL 225 (3) (оригинатор - Maize Research Institute, Zemun Polje, г. Белград, Сербия) в фазу 3-го листа (лабораторный опыт). Представлены характерные нормированные ИК-спектры.

Мы обнаружили, что колебания свободной и связанной ОН-группы и колебания внутри- и межмолекулярных Н-связей в хлоропластах листа, а также валентные колебания $\mathrm{N}-\mathrm{H}$ связей в первичных и вторичных амидах белков, колебания связей гидроксильной ОН-группы (вода, углеводы, аминокислоты) и валентные колебания связей NH-группы (белки, аминокислоты и их производные) максимальны для линии ZPPL 186 и минимальны для линии ZPPL 225 (область 3500-3000 см-1). У линии ZPPL 186 для хлоропластов листа также характерен максимальный вклад валентных колебаний алканов, карбоновых кислот (область 2920-2860 см-1) и деформационных колебаний связей в ароматических соединениях (полоса $1000 \mathrm{~cm}^{-1}$ ), у линии M1-3-3-sdms - колебаний связей O-C-O (полоса $2300 \mathrm{~cm}^{-1}$ ). Таким образом, нами выявлены различия в составе молекул белков и углеводов в хлоропластах листа различных линий кукурузы. Эти различия могут быть обусловлены синтезом новых молекул целлюлозы, белков, углеводов, эфиров, фенолов. Например, большее содержание молекул алканов, карбоновых кислот, а также ароматических соединениях в хлоропластах листа было характерно для ZPPL 186.

Однако с помощью ИК-спектроскопии мы не смогли выявить различия в области от 1100 до $1600 \mathrm{~cm}^{-1}$ (см. рис. 1). Известно, что эта область характерна для симметричных и антисимметричных валентных колебаний 
атомов, а также плоскостных и внеплоскостных деформационных колебаний молекул $(14,15)$. Возможными кандидатами для таких различий могли быть молекулы целлюлозы и каротиноидов из хлоропластов листа. Для изученных нами линий кукурузы характерно высокое содержание крахмала, целлюлозы и каротиноидов в тканях листа (22). Поэтому в следующей серии экспериментов мы получили ИК-спектры целлюлозы, которые характеризовались полосами в области 4000-2500 cм-1 (валентные колебания О-Н и С-Н связей) и полосами в области 1500-500 $\mathrm{cm}^{-1}$ (область валентных колебаний $\mathrm{C}-\mathrm{C}, \mathrm{C}-\mathrm{O}$ связей и деформационные колебания $\mathrm{C}-\mathrm{H}$ и $\mathrm{O}-\mathrm{H}$ связей). Область колебаний ОН-групп включала три полосы, соответствующие свободным гидроксильным группам (у атомов углерода С2 и С6) и ОН-группе, которые вовлечены в водородные связи (рис. 2).

A

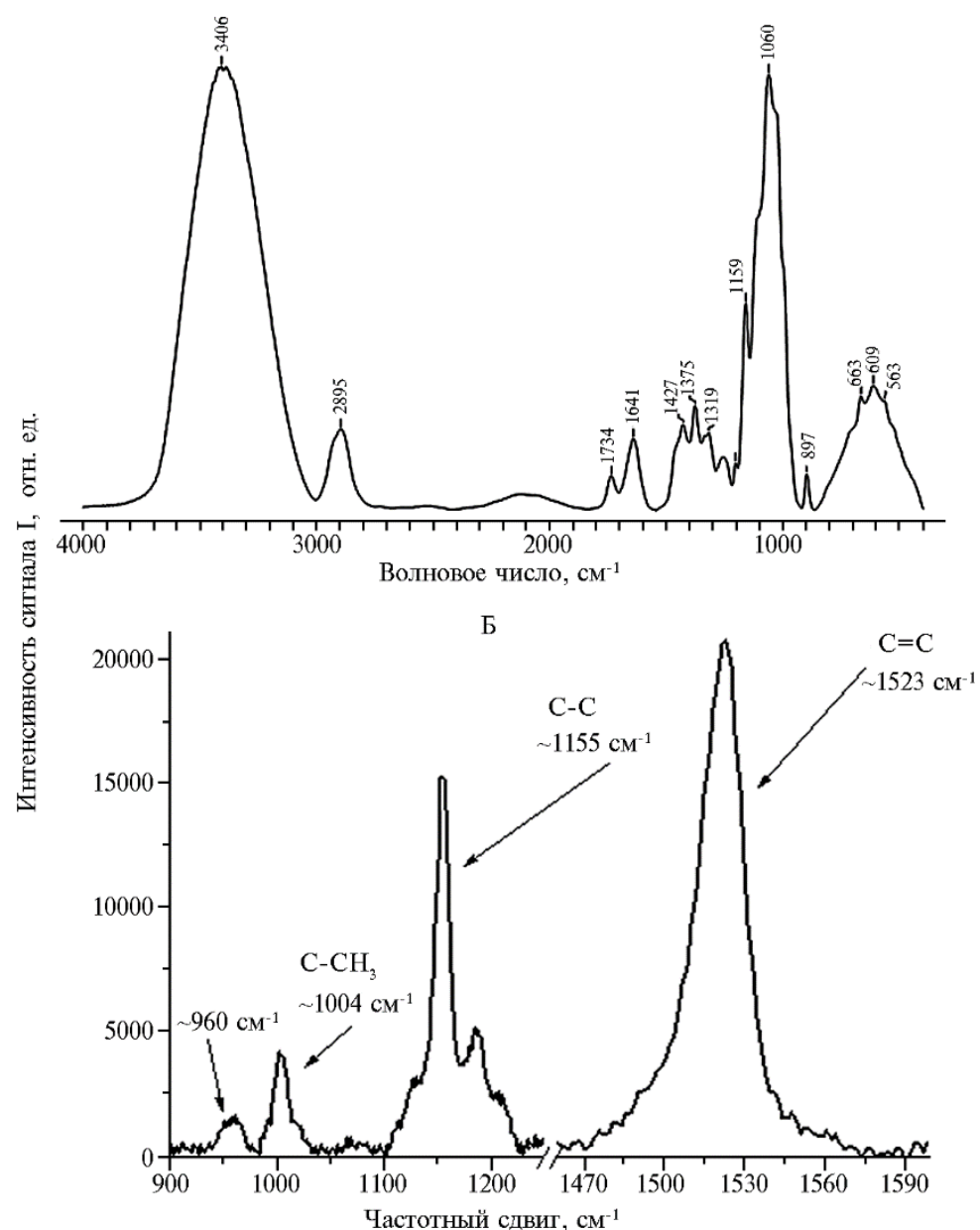

Рис. 2. ИК-спектры целюлозы из ткани листа (инфракрасная спектроскопия с преобразованием Фурье, А) и спектры комбинационного рассеяние (КР) каротиноидов в хлоропластах листьев (Б) у кукурузы (Zea mays L.) линии ZPPL 186 (оригинатор - Maize Research Institute, Zemun Polje, г. Белград, Сербия) в фазу 3-го листа (лабораторный опыт). Представлены характерные нормированные ИК- и КР-спектры.

Внутримолекулярные водородные связи между гидроксильными группами в положениях С2 и С6 (равно как и в С3) образуются даже в присутствии малых количеств ОН-групп. В ИК-спектре в области 1500$900 \mathrm{~cm}^{-1}$ мы регистрировали суммарную интенсивность колебаний трех гидроксильных групп, входящих в состав каждого глюкопиранозного звена мо- 
лекулы целлюлозы (колебания $\mathrm{C}-\mathrm{H}, \mathrm{C}-\mathrm{O}$ и $\mathrm{O}-\mathrm{H}$ связей), а полосы при 1375 и $1319 \mathrm{~cm}^{-1}$ характеризовали наличие и проявление деформационных колебаний соответственно $\mathrm{C}-\mathrm{H}$ - и $\mathrm{CH}_{2}$-групп в молекуле целлюлозы (8, 14). Однако с помощью ИК-спектроскопии нам не удалось обнаружить различия в исследуемой области волновых чисел для молекул целлюлозы.

В следующей серии экспериментов для уточнения результатов ИКспектроскопии в области 800-1800 $\mathrm{cm}^{-1}$ мы использовали КР-спектроскопию. Важно, что именно КР-спектры хлоропластов листа кукурузы в указанной области характеризуются высокоамплитудными полосами каротиноидов и низкоамплитудными или совмещенными полосами молекул целлюлозы (полоса $1095 \mathrm{~cm}^{-1}$ соответствует колебаниям связей $\mathrm{C}-\mathrm{O}-\mathrm{C}$, a $1477 \mathrm{~cm}^{-1}$ - колебаниям Н-C-H групп атомов молекулы целлюлозы). Таким образом, с помощью КР-спектроскопии в области 800-1800 cм-1 можно дополнительно исследовать конформацию молекул каротиноидов в хлоропластах (см. рис. 2, табл.) (24-27). В КР-спектрах полоса $1523 \mathrm{~cm}^{-1}$ характеризует колебания связей $\mathrm{C}=\mathrm{C}$ в молекуле каротиноида, полоса $1155 \mathrm{~cm}^{-1}-$ колебания $\mathrm{C}-\mathrm{C}$ связей. В случае транс-конформации двойных связей в молекуле каротиноида полоса при $1155 \mathrm{~cm}^{-1}$ изменяется и приобретает два выраженных плеча - при 1190-1193 и $1210 \mathrm{~cm}^{-1}$. Полоса $1004 \mathrm{~cm}^{-1}$ соответствует колебаниям боковой метильной группы C-CH3. Полоса $960 \mathrm{~cm}^{-1} \mathrm{xa}-$ рактеризует внеплоскостные колебания $\mathrm{C}-\mathrm{H}$ в области $\mathrm{C}-\mathrm{C}$ связи, причем увеличение интенсивности этой полосы наблюдается при нарушении плоской конфигурации молекулы: чем большее количество пигмента связано с белком, тем менее выражены внеплоскостные кручения между атомами углерода С11 и С12 и, как следствие, интенсивность указанной полосы в КР-спектре.

Интенсивность (I) и соотношение интенсивности полос в спектрах комбинационного рассеяния каротиноидов в хлоропластах листьев у изученных линий кукурузы (Zea mays L.) в фазу 3-го листа $(n=10)$

\begin{tabular}{|c|c|c|c|c|}
\hline \multirow{2}{*}{$\begin{array}{l}\text { Частотный сдвиг, } \\
\mathrm{cm}^{-1}(M \pm \mathrm{SD})\end{array}$} & \multirow{2}{*}{$\begin{array}{l}\text { Среднее зна- } \\
\text { чение I }(M)\end{array}$} & \multirow{2}{*}{$\begin{array}{l}\text { Стандартное откло- } \\
\text { нение }( \pm \mathrm{SD})\end{array}$} & \multicolumn{2}{|c|}{ Характерные полосы } \\
\hline & & & \begin{tabular}{|l|l|} 
положение соотношение \\
\end{tabular} & е интенсивности \\
\hline \multicolumn{5}{|c|}{ Л и н ия М1-3-3-sdms } \\
\hline $1523,6 \pm 0,1$ & 132,5 & 9,6 & $962 / 1006$ & 0,45 \\
\hline $1155,6 \pm 0,9$ & 148,9 & 10,9 & $1006 / 1157$ & 0,34 \\
\hline $1191,3 \pm 0,4$ & 46,7 & 3,7 & $1157 / 1190$ & 3,18 \\
\hline $1004,9 \pm 0,9$ & 51,9 & 4,2 & $1006 / 1525$ & 0,39 \\
\hline $960,5 \pm 1,3$ & 23,5 & 1,9 & $1526 / 1157$ & 0,88 \\
\hline \multicolumn{5}{|c|}{ Л и н и я ZPPL 186} \\
\hline $1523,0 \pm 0,2$ & 213,6 & 26,9 & $962 / 1007$ & 0,38 \\
\hline $1155,8 \pm 0,7$ & 195,7 & 23,5 & $1007 / 1158$ & 0,28 \\
\hline $1190,4 \pm 0,4$ & 55,4 & 7,3 & $1158 / 1190$ & 3,53 \\
\hline $1004,0 \pm 0,6$ & 55,3 & 4,5 & $1007 / 1526$ & 0,25 \\
\hline $960,1 \pm 0,5$ & 21,5 & 2,2 & $1526 / 1158$ & 1,09 \\
\hline \multicolumn{5}{|c|}{ Л и н и я ZPPL 225} \\
\hline $1523,8 \pm 0,3$ & 118,2 & 13,6 & $960 / 1005$ & 0,48 \\
\hline $1155,2 \pm 0,6$ & 132,1 & 21,2 & $1005 / 1157$ & 0,36 \\
\hline $1189,7 \pm 0,9$ & 43,4 & 6,7 & $1157 / 1189$ & 3,04 \\
\hline $1004,6 \pm 0,4$ & 47,7 & 5,6 & $1005 / 1526$ & 0,40 \\
\hline $960,7 \pm 0,3$ & 23,0 & 2,4 & $1526 / 1157$ & 0,89 \\
\hline
\end{tabular}

При анализе КР-спектров каротиноидов для нормировки вклада каждого типа связей используют соотношения величины пиков, выбирая, как правило, постоянную по амплитуде полосу КР, изменения которой при изучаемом процессе минимальны (внутримолекулярный маркер) (23). Полученные нами результаты указывают на то, что в различных линиях кукурузы каротиноиды в хлоропластах могут находиться в разных конформационных состояниях. Так, конформация, обусловленная длиной полиеновой цепи молекул каротиноида (величина пропорциональна I $1523 / \mathrm{I}_{1155}$ ), в хлоро- 
пластах листа линий кукурузы может варьировать от 0,88 (M1-3-3-sdms) до 1,09 (ZPPL 186), и у двух образцов линий кукурузы (кроме ZPPL 225) молекулы каротиноидов находятся в 15-trans форме. При такой конформации молекулы полоса $1155 \mathrm{~cm}^{-1} \mathrm{KP}$-спектра характеризуется одним выраженным плечом $1190 \mathrm{~cm}^{-1}$. Отметим, что у линии ZPPL 186 каротиноиды в хлоропластах листа характеризовались минимальным соотношением I960/I1006, что указывает на незначительное изменение конформации, обусловленное поворотом молекулы каротиноида вне плоскости полиеновой цепи, или на отсутствие такого изменения. У линии ZPPL 186 молекула каротиноидов характеризовалась более выраженными колебаниями боковой СН3-группы. Известно, что каротиноид, связанный с белками светособирающего комплекса фотосистемы II, характеризуется интенсивной полосой при $960 \mathrm{~cm}^{-1}$ в КРспектре, которая по амплитуде практически не отличается от полос 1156 и $1004 \mathrm{~cm}^{-1}$ (24-27). Отметим, что в наших экспериментах амплитуда полосы $960 \mathrm{~cm}^{-1}$ КР-спектра каротиноидов была существенно меньше амплитуды полос при 1156 и $1004 \mathrm{~cm}^{-1}$ и не различалась в КР-спектре хлоропластов у разных линий, что, вероятно, свидетельствует об отсутствии белок-липидных взаимодействий.

По мнению авторов, совместное использование ИК- и КР-спектроскопии фракции хлоропластов листа можно рекомендовать в качестве малоинвазивного для растения метода контроля за содержанием и возможными различиями в конформации биологических молекул при тестировании линий и гибридов кукурузы (28-30).

Итак, с помощью методов вибронной спектроскопии исследовали изменения содержания и конформации молекул хлоропластов у разных линий кукурузы. Инфракрасная (ИК) спектроскопия (область 3500-3000 см-1) показала, что в молекулах, содержащихся в хлоропластах листа (вода, углеводы, белки), доля колебаний ОН-групп и внутри- и межмолекулярных Нсвязей максимальна у линии кукурузы ZPPL 186, а колебаний NH-групп амидов (белки) минимальна у ZPPL 225. Доказано, что для линии ZPPL 186 характерна максимальная доля колебаний от молекул алканов, карбоновых кислот (область 2920-2860 см-1) и деформационных колебаний ароматических структур (полоса $1000 \mathrm{~cm}^{-1}$ ) хлоропластов, а для линии M1-3-3-sdms доля колебания связей $\mathrm{O}=\mathrm{C}=\mathrm{O}$ (полоса $2300 \mathrm{~cm}^{-1}$ ). C помощью спектроскопии комбинационного рассеяния (КР-спектроскопия) (области 1250-500 $\mathrm{cm}^{-1}$ и 1535-1400 см ${ }^{-1}$ ) обнаружено, что у изученных линий кукурузы выявленные различия связаны с изменениями конформации молекул каротиноидов в хлоропластах, но не молекул целлюлозы. Установлено, что у двух образцов (кроме ZPPL 225) молекулы каротиноидов находятся в 15-trans форме с различной конформацией полиеновой цепи. Отметим, что конформация каротиноидов линии ZPPL 186 характеризуется минимальной величиной поворота вне плоскости полиеновой цепи, при этом проявляются более выраженные колебания боковой СН3-группы. Высказано предположение, что у изученных линий каротиноиды хлоропластов листа не взаимодействуют с ароматическими аминокислотами белков.

\footnotetext{
1'Institut za kukuruz «Zemun Polje»,

11185 Beograd-Zemun, ul. Slobodana Bajica 1, Srbija,

e-mail: radenovic@sbb.rs $₫$, ndelic@mrizp.rs, msecanski@mrizp.rs,

dobropoljac@yahoo.com;

2ФГБОУ ВО Московский государственный университет

им. М.В. Ломоносова, Биологический факультет,
}

Поступила в редакцию 15 июля 2020 года 
119234 Россия, г. Москва, Ленинские горы, МГУ, 1, стр. 12,

Биологический факультет МГУ,

e-mail: maksimov@mail.ru $₫$;

${ }_{3}^{3}$ ГБОУ ВО Национальный исследовательский Мордовский

государственный университет им. Н.П. Огарева,

430005 Россия, Республика Мордовия, г. Саранск,

ул. Большевистская, 68,

e-mail: vshutova@yandex.ru;

${ }^{4}$ Shenzhen MSU-BIT University, Biology Department,

No 299, Ruyi Road, Longgang District,

Shenzhen, Guangdong, 518172 China,

e-mail: haojr@szmsubit.edu.cn;

${ }^{5}$ University of Belgrade, Faculty for Physical Chemistry,

12-16 Studentski trg, 11000 Belgrade, Srbija

Sel'skokhozyaistvennaya biologiya [Agricultural Biology], 2021, V. 56, № 5, pp. 948-957

\title{
USING INFRARED SPECTROSCOPY AND RAMAN SPECTROSCOPY TO EVALUATE THE CONFORMATION OF BIOMOLECULES IN MAIZE (Zea mays L.) LINES
}

\author{
C.N. Radenovich $1,5 \bowtie$, G.V. Maksimov ${ }^{凶}$, V.V.Shutova ${ }^{3}$, J. Hao ${ }^{4}$, N.S. Delich 1 , \\ M.D. Sechansky ${ }^{1}$, A.S. Popovich ${ }^{1}$
}

\begin{abstract}
${ }^{1}$ Maize Research Institute, Zemun Polje, ul. Slobodana Bajicha 1, 11185 Belgrade-Zemun, Serbia, e-mail radenovic@sbb.rs ( $\triangle$ corresponding author), ndelic@mrizp.rs, msecanski@mrizp.rs, dobropoljac@yahoo.com;

${ }^{2}$ Lomonosov Moscow State University, Faculty of Biology, 1-12 Leninskie Gory, Moscow, 119234 Russia, e-mail maksimov@mail.ru ( $₫$ corresponding author);

${ }^{3}$ Ogarev National Research Mordovia State University, 68, ul. Bolshevistskaya, Republic of Mordovia, Saransk, 430005 Russia, e-mail vshutova@yandex.ru;

${ }^{4}$ Shenzhen MSU-BIT University, Biology Department, No 299, Ruyi Road, Longgang District, Shenzhen, Guangdong,

518172 China, e-mail haojr@szmsubit.edu.cn;

${ }^{5}$ University of Belgrade, Faculty for Physical Chemistry, 12-16 Studentski trg, 11000 Belgrade, Srbija

ORCID:

Radenovich C.N. orcid.org/0000-0002-4997-7635

Maksimov G.V. orcid.org/0000-0002-7377-0773

Delich N.S. orcid.org/0000-0003-4020-0114

Sechansky M.D. orcid.org/0000-0003-2070-4366
\end{abstract}

Shutova V.V. orcid.org/0000-0001-6437-3621

Hao J. orcid.org/0000-0003-4256-5969

Popovich A.S. orcid.org/0000-0002-4569-6799

The authors declare no conflict of interests

Acknowledgements:

Supported by GVM from Russian Science Foundation (grant No: 19-79-30062) as well as the Interdisciplinary Scientific and Educational School of Moscow University "Molecular Technologies of Living Systems and Synthetic Biology"

Received July 15, 2020

doi: 10.15389/agrobiology.2021.5.948eng

\section{Abstract}

Currently, there are few non-invasive methods that allow you to control the content and conformation of molecules in plant cells and tissues, not only in the laboratory, but also in the field Infrared microscopy and Raman spectroscopy (IR and Raman spectroscopy) are actively used to analyze the role of molecules of certain substances in crop breeding. Using methods of vibronic spectroscopy, we investigated changes in the content and conformation of chloroplast molecules of various maize lines. Using infrared (IR) spectroscopy $\left(3500-3000 \mathrm{~cm}^{-1}\right)$ it was found that in the chloroplasts, the proportion of vibrations of $\mathrm{OH}$-groups and intramolecular and intermolecular $\mathrm{H}$ bonds is maximum for the maize line ZPPL 186, and vibrations of NH-groups of amides (proteins) is minimal for ZPPL 225. It has been proven that ZPPL 186 chloroplasts are characterized by the maximum proportion of stretching vibrations from alkane molecules, carboxylic acids (region 2920$2860 \mathrm{~cm}^{-1}$ ) and deformation vibrations of aromatic structures (band at $1000 \mathrm{~cm}^{-1}$ ), and for the line M1-3-3-sdms, the fraction of stretching vibrations of $\mathrm{O}=\mathrm{C}=\mathrm{O}$ bonds (band at $2300 \mathrm{~cm}^{-1}$ ) is characteristic. Using Raman spectroscopy (range of $1250-500 \mathrm{~cm}^{-1}$ and $1535-1400 \mathrm{~cm}^{-1}$ ), it was found that differences in the chloroplasts of different maize lines are associated with changes in the conformation of chloroplast carotenoid molecules (rather than cellulose molecules). It was found that in two samples (except ZPPL 225), carotenoid molecules are in the 15-trans form with different conformation of the polyene chain. We note that the conformation of carotenoids of the ZPPL 186 line is characterized by a minimum amount of rotation outside the plane of the polyene chain and has more pronounced vibrations of the lateral $\mathrm{CH}_{3}$-group. It was assumed that carotenoids of leaf chloroplasts of various maize lines lack interactions with aromatic amino acids 
of proteins. According to the authors, the combined use of IR and Raman spectroscopy of the leaf chloroplast fraction can be recommended for monitoring the content and conformation of biomolecules in maize breeding.

Keywords: Zea mays L., inbred line, leaf, chloroplast, Raman spectra, infrared spectra, conformation changes, carbohydrates, carotenoids, proteins, maize breeding.

\section{REFEREN C ES}

1. Radosavljević M., Bekrić V., Božović I., Jakovljević J. Physical and chemical properties of various corn genotypes as a criterion of technological quality. Genetika, 2000, 32(3): 319-329.

2. Konstantinov K., Mladeović Drinić S., Abđelkovič V., Babić M. Ethics in scientific results application: gene and life forms patenting. Genetika, 2010, 42(1): 195-208.

3. Radenović C.N., Maksimov G.V., Tyutyaev E.V., Stanković G.J., Jovanović Z.V., Beljanski M.V. Detecting the phase transition in thylakoid membranes of maize inbred lines by means of delayed fluorescence. Plant Physiology and Biochemistry, 2014, 81: 208-211 (doi: 10.1016/j.plaphy.2014.03.013).

4. Grubbs B.A., Etter N.P., Slaughter W.E., Pittsford A.M., Smith C.R., Schmitt P.D. A low-cost beam-scanning second harmonic generation microscope with application for agrochemical development and testing. Analytical Chemistry, 2019, 91(18): 11723-11730 (doi: 10.1021/acs.analchem.9b02304).

5. Butler H.J., Martin F.L., Roberts M.R., Adams S., McAinsh M.R. Observation of nutrient uptake at the adaxial surface of leaves of tomato (Solanum lycopersicum) using Raman spectroscopy. Analytical Letters, 2020, 53(4): 536-562 (doi: 10.1080/00032719.2019.1658199).

6. Hu F., Shi L., Min W. Biological imaging of chemical bonds by stimulated Raman scattering microscopy. Nature Methods, 2019, 16(9): 830-842 (doi: 10.1038/s41592-019-0538-0).

7. Vlasov A.V., Maliar N.L., Bazhenov S.V., Nikelshparg E.I., Brazhe N.A., Vlasova A.D., Osipov S.D., Sudarev V.V., Ryzhykau Y.L., Bogorodskiy A.O., Zinovev E.V., Rogachev A.V., Manukhov I.V., Borshchevskiy V. I., Kuklin A. I., Pokorný J., Sosnovtseva O., Maksimov G.V., Gordeliy V.I. Raman scattering: from structural biology to medical applications. Crystals, 2020, 10(1): 38 (doi: 10.3390/cryst10010038).

8. Schulz H., Baranska M. Identification and quantification of valuable plant substances by IR and Raman spectroscopy. Vibrational Spectroscopy, 2007, 43(1): 13-25 (doi: 10.1016/j.vibspec.2006.06.001).

9. Eremina O.E., Semenova A.A., Sergeeva E.A., Brazhe N.A., Maksimov G.V., Shekhovtsova T.N., Gudilin E.A., Veselova I.A. Uspekhi khimii, 2018, 87(8): 741-770 (doi: 10.1070/RCR4804) (in Russ.).

10. Schiavon M., Pizzeghello D., Muscolo A., Vaccaro S., Francioso O., Nardi S. High molecular size humic substances enhance phenylpropanoid metabolism in maize (Zea mays L.). J. Chem. Ecol., 2010, 36(6): 662-669 (doi: 10.1007/s10886-010-9790-6).

11. Ertani A., Francioso O., Tinti A., Schiavon M., Pizzeghello D., Nardi S. Evaluation of seaweed extracts from Laminaria and Ascophyllum nodosum spp. as biostimulants in Zea mays L. using a combination of chemical, biochemical and morphological approaches. Front Plant Sci., 2018, 9: 428 (doi: 10.3389/fpls.2018.00428).

12. Radenović Č.N., Maksimov G.V., Shutova V.V., Slatinskaya O.V., Protopopov F.F., Delić N.S., Grchić N.M., Pavlov J.M., Čamdžija Z.F. Complete study of nature and importance of spectral bands contained in infrared spectra of leaves of maize inbred lines with significant breeding properties. Russian Agricultural Sciences, 2019, 45(4): 334-339 (doi: org/10.3103/S106836741904013X).

13. Vollhardt P.C., Schore N.E. Organic shemistry. W.H. Freeman and Company, United States, 1996.

14. Krimm S., Bandekar J. Vibrational spectroscopy and conformation of peptides, polypeptides, and proteins. Advances in Protein Chemistry, 1986, 38: 181-364 (doi: 10.1016/S0065-3233(08)60528-8).

15. Sverdlov L.M., Kovner M.A., Krainov E.P. Kolebatel'nye spektry mnogoatomnykh molekul [Vibrational spectra of polyatomic molecules]. Moscow, 1970 (in Russ.).

16. Merlin J. Resonance Raman spectroscopy of carotenoids and carotenoid-containing systems. Pure and Applied Chemistry, 1985, 57(5): 785-792 (doi: 10.1351/pac198557050785).

17. Amir R.M., Anjum F.M., Khan M.I., Khan M.R., Pasha I., Nadeem M. Application of Fourier transform infrared (FTIR) spectroscopy for the identification of wheat. J. Food Sci. Technol., 2013, 50: 1018-1023 (doi: 10.1007/s13197-011-0424-y).

18. Tyutyaev E.V., Shutova V.V., Maksimov G.V., Radenovich Ch., Grodzinskii D.M. Fiziologiya rastenii i genetika, 2015, 47(2): 147-159 (in Russ.).

19. Berthold D.A., Babcock G.T., Yocum C. F. A highly resolved, oxygen evolving Photosystem II preparation from spinach thylakoid membranes. FEBS Lett., 1981, 134(2): 231-234 (doi: 10.1016/0014-5793(81)80608-4).

20. Lovyagina E.R., Davletshina L.N., Kultysheva M.Yu., Timofeev K.N., Ivanov I.I., Semin B.K. Fiziologiya rastenii, 2005, 52(1): 12-20 (in Russ.).

21. Shutova V., Yusipovich A., Parshina E., Zakharkin D., Revin V. Effect of particle size on the 
enzymatic hydrolysis of polysaccharides from ultrafine lignocellulose particles. Applied Biochemistry and Microbiology, 2012, 48(3): 312-317 (doi: 10.1134/S000368381203012X).

22. Radenović Č., Grodzinskij D.M., Filipović M. The prestigious maize inbred lines and hybrids with erect top leaves are characterised by a property of an efficient photosynthetic model and a satisfactory base for the further progress in breeding and selection. Fiziologiya i biokhimiya kul'turnykh rastenii, 2010, 42(3): 187-201.

23. Shutova V.V., Tyutyaev E.V., Churin A.A., Ponomarev V.Yu, Belyakova G.A., Maksimov G.V. IR and Raman Spectroscopy in the study of carotenoids of Cladophora rivularis algae. Biophysics, 2016, 61(4): 601-605 (doi: 10.1134/S0006350916040217).

24. Robert B. The electronic structure, stereochemistry and resonance Raman spectroscopy of carotenoids. In: The photochemistry of carotenoids. New York, Boston, Dordrecht, London, Moscow, Kluwer Academic Publishers, 2004: 189-201.

25. Hudson S.D., Chumanov G. Bioanalytical applications of SERS (surface-enhanced Raman spectroscopy). Analytical and Bioanalytical Chemistry, 2009, 394(3): 679-686 (doi: 10.1007/s00216009-2756-).

26. Ruban A.V., Berera R., Ilioaia C. van Stokkum IH, Kennis JT, Pascal AA, van Amerongen H, Robert B, Horton P, van Grondelle R. Identification of a mechanism of photoprotective energy dissipation in higher plants. Nature, 2007, 450: 575-578 (doi: 10.1038/nature06262).

27. Gruszecki W.I., Gospodarek M., Grudzinski W. Mazur R, Gieczewska K, Garstka M. Lightinduced change of configuration of the LHCII-Bound xanthophyll (tentatively assigned to violaxanthin): a resonance Raman study. J. Phys. Chem. B, 2009, 113: 2506-2512 (doi: 10.1021/jp8101755).

28. Todorenko D.A., Hao J., Slatinskaya O.V., Allakhverdiev E.S., Khabatova V.V., Ivanov A.D., Radenovic C.N., Matorin D.N., Alwasel S., Maksimov G.V., Allakhverdiev S.I. Effect of thiamethoxam on photosynthetic pigments and primary photosynthetic reactions in two maize genotypes (Zea mays). Functional Plant Biology, 2021, 48(10): 994-1004 (doi: 10.1071/FP21134).

29. Radenović Č., Maksimov G.V., Grodzinskij M.D. Identification of organic molecules in kernels of maize inbred lines displayed with infrared spectra. Plant Physiology and Genetics (Kiev, Ukraine), 2015, 47(1/273): 15-24.

30. Radenović, Č., Filipović M., Selaković D. The prestigious maize inbred lines with erect top leaves. The priority performance of the efficient photosynthetic model in breeding. Genetika, 2009, 41(1): 49-58 (doi: 10.2298/GENSR0901041R). 